\title{
ANALISA LUASAN TERUMBU KARANG DI PERAIRAN PULAU TEGAL LAMPUNG DENGAN TEKNOLOGI PENGINDERAAN JAUH
}

\author{
Faris Muhtar ${ }^{1}$, Armijon$^{2}$, Fauzan Murdapa ${ }^{3}$, Romi Fadly $^{4}$ \\ 1,2,3,4 Program Studi Teknik Geodesi, Fakultas Teknik Universitas Lampung \\ J1. Prof. Dr. Sumantri Brojonegoro No.1 Bandar Lampung 35145 \\ Corresponding author: farismhtar@yahoo.com \\ Manuscript received: June 12, 2019; revised: July 9, 2019; \\ Approved: July 18, 2019; available online: July 26, 2019
}

\begin{abstract}
Abtrak - Kerusakan terumbu karang di Pulau Tegal berdampak terhadap berkurangnya habitat terumbu karang, sehingga perlu dilakukan monitoring. Monitoring dilakukan dengan analisis luasan dan perubahannya dengan memanfaatkan teknologi penginderaan jauh untuk pemetaan kondisi eksistingnya. Data yang digunakan yaitu citra landsat pada tahun 1998, 2008, 2015 dan 2018. Pengolahan citra digital dilakukan mulai dari koreksi citra, perhitungan algoritma lyzenga, interpretasi citra dan validasi lapangan, serta dilakukan uji akurasi habitat terumbu karang menggunakan matriks konfusi. Hasil penelitian menunjukan bahwa terjadi perubahan luasan terumbu karang dari tahun 1998 - 2018. Kelas terumbu karang mengalami pengurangan seluas 11,22 ha. Kelas terumbu karang yang berubah menjadi kelas pasir seluas 9,13 ha $(29,49 \%)$ dan lamun seluas 4,38 ha $(14,15 \%)$. Kelas pasir yang berubah menjadi terumbu karang seluas 2,08 ha $(13,52 \%)$ dan kelas lamun yang berubah menjadi terumbu karang seluas 0,21 ha $(0,25 \%)$. Perubahan yang paling besar yaitu perubahan terumbu karang menjadi pasir seluas 9,13 ha $(29,49 \%)$, sedangkan perubahan paling kecil yaitu perubahan lamun menjadi terumbu karang seluas 0,21 ha $(0,25 \%)$. Pada kelas lainnya perubahan luasan paling besar yaitu perubahan lamun menjadi pasir seluas 5,76 ha $(6,96 \%)$, sedangkan perubahan paling kecil yaitu perubahan pasir menjadi lamun seluas 2,67 ha $(17,35 \%)$.
\end{abstract}

\begin{abstract}
Damage to coral reefs on Tegal Island has an impact on reducing coral reef habitats, so monitoring needs to be done. Monitoring is done by analyzing the extent and changes by utilizing remote sensing technology to map the existing conditions. The data used are Landsat imagery in 1998, 2008, 2015 and 2018. Digital image processing is done starting from image correction, lyzenga algorithm calculation, image interpretation and field validation, and accuracy testing of coral reef habitats using a confusion matrix. The results showed that there was a change in the area of coral reefs from 1998 to 2018. The coral reef class experienced a reduction of 11.22 ha. Coral classes that changed into sand classes were 9.13 ha $(29.49 \%)$ and seagrasses were 4.38 ha $(14.15 \%)$. The class of sand that turned into coral reefs was 2.08 ha $(13.52 \%)$ and seagrass classes that turned into coral reefs were 0.21 ha $(0.25 \%)$. The biggest change is the change in the coral reef to sand covering an area of 9.13 ha $(29.49 \%)$, while the smallest change is the change in seagrass into a coral reef covering an area of 0.21 ha $(0.25 \%)$. In the other classes, the biggest change in area was seagrass change into sand covering an area of 5.76 ha $(6.96 \%)$, while the smallest change was the change in the sand to seagrass covering an area of 2.67 ha $(17.35 \%)$.
\end{abstract}

Keywords: Coral reefs, Lyzenga algorithm, Landsat imagery

\section{How to cite this article.}

Muhtar, F., Armijon, Murdapa, F. dan Fadly, R. 2019. Analisa Luasan Terumbu Karang di Perairan Pulau Tegal Lampung dengan Teknologi Penginderaan Jauh. Jurnal Geofisika Eksplorasi, 5 (2) p.141-153. doi: 10.23960/

jge.v5i2.29 


\section{PENDAHULUAN}

Terumbu karang merupakan salah satu potensi sumber daya laut di Indonesia yang sangat besar. Hal ini disebabkan ekositem terumbu karang paling produktif dalam mendukung kehidupan masyarakat setempat khususnya nelayan. Jika terumbu karang dijaga secara optimal, maka potensi ikan akan menjadi sumber pendapatan nelayan setempat. Namun beberapa dekade terakhir, kondisi terumbu karang yang dimiliki oleh Indonesia saat ini $7 \%$ terumbu karang kondisinya sangat baik, $33 \%$ baik, $45 \%$ rusak dan $15 \%$ lainnya kondisinya sudah kritis (Suharsono, 1998).

Kerusakan terumbu karang di Indonesia lebih banyak disebabkan oleh berbagai kegiatan manusia dalam pemanfaatan sumber daya lautnya. Penangkapan ikan dengan cara pengeboman dan penggunaan racun sianida, penambangan karang batu, kegiatan selam bawah air, penambatan perahu dengan alat jangkar, pencemaran air oleh limpasan minyak dari kapal dan perahu, serta konversi hutan mangrove menjadi lahan pertambakan merupakan bentuk-bentuk kegiatan yang selama ini berdampak terhadap rusaknya terumbu karang (Yusuf, 2013). Provinsi Lampung menjadi salah satu wilayah yang tidak luput dari kerusakan terumbu karang. Salah satu yang perlu diperhatikan yaitu Pulau Tegal yang merupakan pusat destinasi wisata Provinsi Lampung.

Kawasan perairan Pulau Tegal merupakan bagian dari wilayah perairan Teluk Lampung yang berada di Kecamatan Padang Cermin Kabupaten Pesawaran Provinsi Lampung. Pulau Tegal memiliki topografi berupa pantai pasir putih yang landai (Sebelah Barat, Selatan, Timur, dan Utara), pantai berbatu (sebelah Timur Laut, Tenggara, Barat Daya, dan Barat Laut). Pulau Tegal merupakan pulau berpenghuni $( \pm 15$ KK) yang memiliki teluk-teluk kecil, seperti Teluk Bajo dan Teluk Pengantin. Saat ini Pulau Tegal telah menjadi tujuan ekowisata yang cukup digemari di Lampung. Keberadaan terumbu karang menjadikan Pulau Tegal sebagai destinasi wisata unggulan
Provinsi Lampung. Berdasarkan penelitian yang dilakukan Hartoni pada tahun 2011, mengemukakan bahwa kondisi terumbu karang di perairan Pulau Tegal dikategorikan kondisi sedang dengan rata-rata tutupan karang sebesar $49,87 \%$. Kerusakan terumbu karang di Pulau Tegal disebabkan oleh aktivitas pengeboman, penambangan karang untuk bahan bangunan dan souvenir, jangkar kapal, wisata bahari dan budidaya laut (Hartoni, 2011). Kerusakan terumbu karang berdampak terhadap berkurangnya luasan terumbu karang pada wilayah tersebut. Untuk mengatasi permasalahan tersebut, proses monitoring terumbu karang menjadi satu langkah penting dalam konservasi sumber daya marine agar dapat mengetahui dinamika kondisi ekosistem terumbu karang secara periodik. Monitoring sebaran terumbu karang dapat dilakukan dengan melakukan pemetaan terumbu karang untuk mengetahui berapa banyak luasan terumbu karang yang berkurang. Salah satu cara untuk memetakan sebaran terumbu karang adalah dengan teknologi penginderaan jauh menggunakan algoritma Lyzenga guna mengetahui seberapa banyak terumbu karang yang berkurang secara temporal dengan interval waktu 10 tahun dengan pola time series. Data yang digunakan yaitu data citra satelit landsat tahun 1998, tahun 2008, tahun 2015, dan tahun 2018 untuk mengetahui luasan dan perubahannya di perairan Pulau Tegal. Selain data dengan interval 10 tahun, data citra yang digunakan yaitu data citra landsat tahun 2015 untuk mengetahui informasi spasial luasan dan perubahannya karena pada tahun 2015 telah dilakukan survey lapangan oleh tim LAPAN terhadap kondisi biofisik Pulau Tegal dan sebagai acuan untuk melakukan survey tahun 2018.

Penelitian ini penting dilakukan untuk mengetahui perubahan yang terjadi terhadap luasan terumbu karang. Dengan demikian penelitian ini diharapkan membantu pemerintah daerah dalam menentukan kebijakan untuk konservasi terumbu karang khususnya di Pulau Tegal.

Tujuan dalam penelitian ini adalah sebagai berikut: 
1. Melakukan klasifikasi dan pemetaan terumbu karang dengan menggunakan algoritma Lyzenga.

2. Melakukan pengujian terhadap hasil klasifikasi.

3. Menghitung luasan terumbu karang di Pulau Tegal pada tahun 1998, tahun 2008, tahun 2015, dan tahun 2018.

4. Melakukan analisis luasan dan perubahannya yang sudah dilakukan pengujian.

\section{TINJAUAN PUSTAKA}

\subsection{Penginderaan Jauh}

Penginderaan jauh adalah ilmu dan seni untuk mendapatkan informasi tentang objek, daerah, fenomena alam dengan cara menganalisa data yang diperoleh tanpa kontak langsung dengan objek, daerah, fenomena yang dikaji (Lillesand dan Kiefer, 1979). Sistem penginderaan jauh dapat membantu memberikan data penyebaran terumbu karang cukup efektif, karena dalam waktu yang relatif cepat dan biaya murah bisa mencakup wilayah yang sangat luas. Penginderaan jauh untuk terumbu karang memanfaatkan sinar radiasi elektromagnetik pada daerah spektrum sinar tampak. Spektrum sinar tampak dapat menembus air sehingga dapat mendeteksi terumbu karang yang berada di bawah permukaan air. Salah satu citra penginderaan jauh yang dapat digunakan untuk mendeteksi terumbu karang yaitu Citra Landsat 5 dan Landsat 8. Penginderaan jauh untuk terumbu karang memanfaatkan sinar radiasi elektromagnetik pada daerah spektrum sinar tampak. Spektrum ini dapat menembus air sehingga dapat mendeteksi terumbu karang yang berada di bawah permukaan air. Salah satu citra yang digunakan untuk memperoleh informasi objek perairan dangkal khususnya terumbu karang adalah Citra Landsat 5 dan Landsat 8. Pada citra Landsat 5 saluran gelombang elektromagnetik yang digunakan untuk melakukan pemetaan terumbu karang pada perairan dangkal yaitu spektrum sinar biru pada saluran pertama dengan range panjang gelombang $(0,45 \mu m-0,52 \mu m)$, sinar hijau pada saluran kedua dengan range panjang gelombang $(0,52 \mu \mathrm{m}-0,60 \mu \mathrm{m})$, dan sinar merah pada saluran ketiga dengan range panjang gelombang $(0,63 \mu \mathrm{m}-0,69 \mu \mathrm{m})$. Sedangkan pada citra Landsat 8 saluran gelombang elektromagnetik yang digunakan untuk melakukan pemetaan terumbu karang pada perairan dangkal yaitu spektrum sinar biru pada saluran kedua dengan range panjang gelombang $(0,452 \mu m-0,512 \mu m)$, sinar hijau pada saluran ketiga dengan range panjang gelombang $(0,533 \mu \mathrm{m}-0,590 \mu \mathrm{m})$, dan sinar merah pada saluran keempat dengan range panjang gelombang $(0,636 \mu m-0,673$ $\mu m$ ). Makin kecil panjang gelombangnya, maka spektrum tersebut makin dapat menembus air, sehingga berdasarkan pembagian tersebut di atas, maka sinar birulah yang paling dalam dapat menembus air (Susilo, 1997).

\subsection{Pengolahan Citra}

Pengolahan citra yang dilakukan untuk identifikasi terumbu karang yaitu melakukan perbaikan kualitas citra (image enhancement), kalibrasi radiometrik, dan koreksi kolom air (lyzenga).

\subsubsection{Perbaikan Kualitas Citra (Image Enhancement)}

1. Pengubahan Kecerahan Gambar (Image Brightness)

Kecerahan/kecemerlangan gambar dapat diperbaiki dengan menambahkan (atau mengurangkan) sebuah konstanta kepada atau dari setiap pixel di dalam citra. Akibat dari operasi ini, histogram citra mengalami pergeseran.

2. Peregangan Kontras

Kontras menyatakan sebaran terang (lightness) dan gelap (darkness) di dalam sebuah gambar. Citra dapat dikelompokkan ke dalam tiga kategori kontras yaitu citra kontras rendah (low contrast), citra kontras bagus (good contrast atau normal contrast), dan citra kontras tinggi (high contrast).

3. Pengubahan Histogram Citra

Terdapat dua cara pengubahan citra berdasarkan histogram yaitu perataan 
histogram (histogram equalization) dengan cara nilai-nilai intensitas di dalam citra diubah sehingga penyebarannya seragam (uniform) dan pembentukan histogram (histogram spesification) dengan cara nilai-nilai intensitas di dalam citra diubah agar diperoleh histogram dengan bentuk yang dispesifikasikan oleh pengguna.

\subsubsection{Kalibrasi radiometrik}

Kalibrasi radiometrik merupakan perhitungan ulang nilai DN (Digital Number) pada gambar atau citra berdasarkan beberapa faktor, seperti waktu perekaman citra, nilai yang diketahui dari bayangan sensor kamera pada bidang datar perekaman, daerah gelap pada citra dan faktor lainnya yang berhubungan dengan karakteristik sistem pencitraan (Jaelani, 2016).

Untuk citra Landsat 8 yang digunakan dalam penelitian ini memiliki resolusi radiometrik 16 bit yang setara dengan 216 (2 pangkat 16), yang berarti rentang nilai $\mathrm{DN}$ (Digital Number) pada citra Landsat 8 ini berada pada rentang 0 sampai 216 (2 pangkat 16) atau sama dengan 65536. Tujuan dari kalibrasi radiometrik adalah untuk mengubah nilai DN kedalam nilai satuan output yang lain, supaya nilai tersebut dapat diproses pada pengolahan citra selanjutnya. Adapun proses konversi nilai DN yaitu:

1. DN menjadi Top of Atmosphere (ToA) Radiance.

$$
\begin{aligned}
& L_{\lambda}=M_{L} Q_{c a l}+A_{L} \ldots \ldots \ldots \ldots \ldots \ldots \ldots . . . \\
& \text { Dimana: } \\
& L_{\lambda}: \text { Spektral radian } \\
& M_{L}: \text { RADIANCE_MULT_BAND_x } \\
& \text { yang didapat dari metada } \\
& A_{L}: \text { RADIANCE_ADD_BAND_x } \\
& \text { yang didapat dari metadata } \\
& Q_{\text {cal }}: \text { Nilai DN }
\end{aligned}
$$

2. DN menjadi Top of Atmosphere (ToA) Reflectance.

$$
\begin{aligned}
& \rho \lambda^{\prime}=M_{\rho} Q_{c a l}+A_{\rho} \ldots \ldots \ldots \ldots \ldots \ldots \ldots . . . . . . . . . . . \\
& \text { Dimana: } \\
& \rho \lambda^{\prime}: \text { Spektral reflektan tanpa koreksi } \\
& \text { sudut matahari. } \\
& M_{\rho}: \text { REFLECTANCE_MULT_BAND_x } \\
& \quad \text { yang didapat dari metada). }
\end{aligned}
$$

$$
\begin{aligned}
& A_{\rho}: \text { REFLECTANCE_ADD_BAND_x } \\
& \text { yang didapat dari metadata } \\
& Q_{\text {cal }}: \text { Nilai DN }
\end{aligned}
$$

\subsubsection{Algoritma Lyzenga}

Secara teoritis jika dasar perairan terlihat, maka dapat dibentuk suatu hubungan antara kedalaman perairan dengan sinyal pantul yang diterima oleh sensor. Namun kenyataannnya tidak, karena hal ini banyak dipengaruhi oleh parameter lain, seperti kekeruhan air, kandungan klorofil, suspensi sedimen, pantulan dasar perairan dan pembiasan pada atmosfer (Lyzenga, 1981).

Pengaruh ini dapat dihitung, jika pada setiap titik di suatu wilayah diketahui kedalaman dan karakteristik optis airnya, maka pada lautan yang luas, sifat optis air dianggap seragam akibat percampuran horizontal, sedangkan kedalaman air sangat bervariasi dan secara umum tidak dapat diketahui pada tempat tersebut. Prinsip ini mendasari Lyzenga (1978) untuk mengembangkan teknik penggabungan informasi dari beberapa saluran spectral untuk menghasilkan indeks pemisah kedalaman (depth-invariant index) dari material penutup dasar perairan. Parameter masukan dalam algoritma ini adalah perbandingan antara koefisien pelemahan air (water attenuation coefficient) pada beberapa saluran spectral. Algoritma ini menyadap informasi material penutup dasar perairan berdasarkan kenyataan bahwa sinyal pantulan dasar mendekati fungsi linier dari pantulan dasar perairan dan merupakan fungsi eksponensial dari kedalaman.

Jika dasar perairan laut dangkal dapat terlihat, maka dapat dibentuk suatu hubungan antara kedalaman perairan dengan sinyal pantul yang diterima oleh sensor. Rumus yang dijadikan acuan adalah Exponential Attenuation Model.

$$
\begin{aligned}
L_{i(H)}= & L_{i}+\left(A_{i}+L_{i}\right)^{-2 K_{i} H} \ldots \ldots \ldots \ldots \ldots \ldots(3) \\
\text { dimana: } & \\
L_{i(H)}= & \text { pantulan pada band i dengan } \\
& \text { kedalaman } \mathrm{H}(\mathrm{m}) \\
L_{i} \quad= & \text { pantulan dari laut dalam pada band }
\end{aligned}
$$




$$
\begin{aligned}
& A_{i}=\text { albedo dasar pada band } \mathrm{i} \\
& H=\text { kedalaman perairan }(\mathrm{m}) \\
& K_{i}=\text { koefisien atenuasi air pada band } \mathrm{I} \\
& \quad\left(\mathrm{m}^{-1}\right)
\end{aligned}
$$

Pemetaan perairan dangkal untuk melihat sebaran terumbu karang dapat dilakukan dengan penajaman citra yakni dengan menggunakan algoritma yang disusun oleh Lyzenga (1978) dan dikembangkan di perairan Indonesia (Siregar, 2010).

$$
\begin{aligned}
& Y=(\ln \text { band } 1)+\left(\frac{K_{i}}{K_{j}} \times \ln \text { band } 2\right) \ldots . .(4) \\
& Y \quad=\text { citra hasil ekstrasi dasar perairan } \\
& \text { band } 1=\text { nilai reflektansi kanal biru } \\
& \text { band } 2 \text { = nilai reflektansi kanal hijau } \\
& K_{i} / K_{j}=\text { nilai koefisien atenuasi } \\
& \text { dimana: } \\
& K_{i} / K_{j}=a+(a+1)^{\frac{1}{2}} \\
& \text { dimana: } \\
& a=\frac{(\text { varian band } 1-\text { varian band } 2)}{(2 \times \text { covarian band } 1 \text { dan band } 2)} . \\
& \text { Varian = nilai ragam dari nilai digital } \\
& \text { Covarian }=\text { nilai koefisien keragaman dari } \\
& \text { nilai digital } \\
& a=\text { Variabel varians dan kovarians }
\end{aligned}
$$

Algoritma Lyzenga atau yang disebut juga Depth-Invariant Index (DII) merupakan algoritma yang diterapkan pada citra untuk koreksi kolom perairan. Pada prinsipnya metode ini menggunakan kombinasi band sinar tampak citra satelit. Teknik ini diuji coba pada perairan Bahama dimana perairan tersebut merupakan perairan yang jernih. Sebelumnya teknik ini digambarkan untuk mengetahui kondisi dasar perairan dengan menggunakan citra Landsat berdasarkan nilai pantulan dasar perairan yang diduga dari fungsi linear reflektansi dasar perairan dan fungsi ekponensial kedalaman air (Lyzenga, 1981).

Dengan menggunakan ekstraksi informasi pada persamaan tersebut, setiap piksel akan terkonversi menjadi indeks tipe dasar perairan yang terbebas dari pengaruh kedalaman. Nilai indeks piksel dari citra yang telah ditransformasikan dari penurunan algorithma Lyzenga dapat menunjukkan identifikasi kelas-kelas obyek perairan dangkal.

\section{METODE PENELITIAN}

Teknologi penginderaan jauh digunakan untuk pemetaan sebaran terumbu karang dengan cara melakukan analisis luasan dan perubahannya di perairan pulau Tegal. Data yang digunakan yaitu data citra satelit Landsat dengan memakai 3 band yaitu band biru, hijau, dan merah. Pada proses pengolahan data citra terdapat beberapa langkah untuk mengetahui sebaran habitat dasar perairan di Pulau Tegal, yaitu peningkatan mutu citra (image enhancement), koreksi atmosfer, cropping, koreksi geometrik, masking citra, transformasi lyzenga, dan klasifikasi unsupervised, serta dilakukan uji akurasi

Peningkatan mutu citra dilakukan dengan penajaman kontras, komposit warna (color composit), dan penapisan (filtering) seperti pada Gambar 1 dan Gambar 2. Penajaman kontras dilakukan untuk mengubah nilai spektral citra asli menjadi citra baru, sehingga kekontrasan antar obyek menjadi lebih tinggi (kontras). Komposit warna dilakukan dengan penggabungan beberapa saluran (band) agar dapat menonjolkan fenomena permukaan bumi yang lebih interpretative. Penapisan dilakukan untuk menghilangkan variasi spektral tertentu sehingga menghasilkan citra baru yang ekspresif dalam menonjolkan polapola tertentu.

Setelah citra dapat lebih mudah diinterpretasikan untuk suatu tujuan tertentu dilakukan proses koreksi atmosfer Dark Object Substraction (DOS) (Gambar 3). Koreksi atmosfer Dark Object Substraction (DOS) menggunakan pendekatan bahwa nilai reflektan piksel seluruh citra dikurangi oleh nilai reflektan obyek tergelap.

Selanjutnya dilakukan pemotongan citra seperti pada Gambar 4. Pemotongan citra atau cropping citra ini dilakukan dengan tujuan yaitu untuk memfokuskan area penelitian. Pemotongan citra dilakukan menggunakan Region of Interest (ROI). 
Proses koreksi geometrik dilakukan pada citra yang telah dipotong, tujuannya untuk memfokuskan citra pada wilayah penelitian, hal ini dapat meminimalkan titik GCP yang akan digunakan sebagai proses validasi lapangan. Titik yang digunakan pada proses uji akurasi geometrik sebanyak 10 titik dengan titik persebaran berada pada tepi-tepi pulau yang dianggap tidak mengalami perubahan.

Sebelum dilakukannya klasifikasi perlu dilakukannya pemisahan antara daratan dan lautan yang dapat dilihat pada Gambar 5 dan Gambar 6. Dalam proses ini hanya perlu mempertimbangkan radiansi spektral dari objek dasar perairan. Masking yang menjadi pemisah antara daratan dan lautan menggunakan band merah dan band inframerah dekat pada landsat 5, kemudian pada landsat 8 menggunakan band inframerah dekat dan band inframerah gelombang pendek. Perhitungan algoritma lyzenga terdiri dari beberapa langkah, yaitu pemilihan sampel pasir dan perhitungan koefisien atenuasi. Pemilihan sampel pasir menggunakan ROI (Region of Interset) bertujuan mengetahui nilai radian pada perairan laut dangkal pada kedalaman berbeda-beda. Dimana nilai dari ROI tersebut digunakan dalam perhitungan nilai varian dan kovarian setiap band yang akan digunakan untuk perhitungan algoritma. Untuk mendeteksi terumbu karang dimana nilai koefisien band 1 dan band 2 dari proses perhitungan algoritma lyzenga akan dimasukan dalam penggabungan band tersebut menjadi satu kanal. Pada landsat 5 adalah penggabungan band 1 dan 2 menggunakan band math, sedangkan landsat 8 adalah penggabungan band 2 dan 3 .

Klasifikasi yang digunakan adalah klasifikasi Unsupervised dengan melakukan penggolongan berdasarkan daerah yang dikehendaki (Gambar 7). Proses klasifikasi dilakukan agar objek yang sama pada data citra diwakili oleh satu warna saja, sehingga nantinya objek-objek dapat dibedakan berdasarkan warna.

Pengujian akurasi terhadap hasil klasifikasi dilakukan dengan matriks konfusi dan data lapangan. Pada prinsipnya, confusion matrix menyusun data hasil klasifikasi dan hasil pengamatan di lapangan dalam sebuah tabel perbandingan persentase dapat dilihat pada Tabel 1. Teknik pengambilan sampel yang digunakan adalah stratified random sampling. Metode ini merupakan suatu teknik sampling dimana populasi dipisahkan ke dalam kelompok-kelompok yang tidak tumpang tindih (overlapping) yang disebut sebagai bub populasi (strata), kemudian dari setiap strata tersebut diambil sampel secara acak (random sampling). Jumlah sampel yang harus diambil proporsional terhadap luasan terumbu karang dan kelas lain yang ada. Verifikasi lapangan dilakukan dengan pengecekan lapangan serta pengukuran GPS beberapa titik sampel dengan menggunakan tracking area dengan mengambil koordinat GCP dan deskripsi lapangan

Metode analisis data yang digunakan dalam penelitian ini adalah metode overlay peta. Teknik yang digunakan untuk overlay peta pada penelitian ini adalah intersect overlay, untuk menghasilkan output dengan atribut yang memiliki data atribut dari kedua theme. Dari hasil overlay tersebut dapat diketahui total perubahan luasan terumbu karang di wilayah pesisir Pulau Tegal Kecamatan Padang Cermin tahun 1998-2018.

\section{HASIL DAN PEMBAHASAN}

\subsection{Luasan Terumbu Karang}

Berdasarkan perhitungan luasan masingmasing kelas pada citra tahun 1998, tahun 2008, tahun 2015 dan tahun 2018 menunjukkan perbedaan luasan, dapat dilihat pada Tabel 2. Luasan terumbu karang pada tahun 1998 - 2018 berkurang 11,22 ha. Sedangkan kelas lainnya bertambah seperti pada tahun 1998-2018, yaitu kelas pasir bertambah 9,03 ha, dan kelas lamun bertambah 2,36 ha.

\subsection{Perubahan Luasan Terumbu Karang}

Berdasarkan perhitungan luasan pada masing-masing kelas, yaitu terumbu karang, pasir, dan lamun diperoleh trend perubahan 
luasan dari tahun ketahun. Dapat dilihat pada Gambar 8.

Pada kelas terumbu karang memperlihatkan trend penurunan. Kelas terumbu karang mengalami penurunan luasan seluas 3,82 ha pada tahun 1998-2008. Kemudian pada tahun 2008-2015 kembali mengalami penurunan luasan seluas 5,47 ha. Penurunan luasan kembali terjadi pada tahun 2015-2018 seluas 1,93 ha. Jika dihitung dalam jangka panjang trend kelas terumbu karang mengalami penurunan seluas 11,22 ha pada tahun 1998-2018.

Trend pada kelas pasir memperlihatkan peningkatan pada tahun 1998-2008, kemudian pada tahun 2008-2015 trend mengalami peningkatan, dan mengalami penurunan pada tahun 2015-2018. Adapun pada tahun 19982008 kelas pasir mengalami penambahan luasan seluas 7,27 ha. Kemudian mengalami penambahan luasan seluas 17,77 ha pada tahun 2008-2015. Penurunan luasan terjadi pada tahun 2015-2018 seluas 16,01 ha. Walaupun pada beberapa tahun sempat mengalami peningkatan luasan, namun dalam jangka panjang trend mengalami peningkatan pada tahun 1998-2018 sehingga jika dihitung dari tahun 1998-2018 kelas pasir mengalami penambahan luasan seluas 9,03 ha.

Trend pada kelas lamun memperlihatkan penurunan pada tahun 1998-2008, kemudian pada tahun 2008-2015 trend mengalami penurunan, dan kembali mengalami peningkatan pada tahun 2015-2018. Adapun pada tahun 1998-2008 kelas lamun mengalami penurunan luasan seluas 3,45 ha. Kemudian mengalami penurunan luasan seluas 12,3 ha pada tahun 2008-2015. Peningkatan luasan kembali terjadi pada tahun 2015-2018 seluas 18,11 ha. Walaupun pada beberapa tahun sempat mengalami penurunan, namun dalam jangka panjang trend mengalami peningkatan pada tahun 1998-2018 sehingga jika dihitung dari tahun 1998-2018 kelas lamun mengalami penambahan luasan seluas 2,36 ha.

Hasil perhitungan luasan masing-masing kelas yakni terumbu karang, pasir, dan lamun pada tahun 1998-2018 mengalami perubahan kelas dan luasan yaitu:
1. Perubahan kelas terumbu karang menjadi pasir yaitu kelas terumbu karang pada tahun 1998 seluas 30,96 ha mengalami perubahan menjadi pasir seluas 9,13 ha pada tahun 2018.

2. Perubahan kelas terumbu karang menjadi lamun yaitu kelas terumbu karang pada tahun 1998 seluas 30,96 ha mengalami perubahan menjadi lamun seluas 4,38 ha pada tahun 2018 .

3. Perubahan kelas pasir menjadi lamun yaitu kelas pasir pada tahun 1998 seluas 15,39 ha mengalami perubahan menjadi lamun seluas 2,67 ha pada tahun 2018 .

4. Perubahan kelas pasir menjadi terumbu karang yaitu kelas pasir pada tahun 1998 seluas 15,39 ha mengalami perubahan menjadi terumbu karang seluas 2,08 ha pada tahun 2018 .

5. Perubahan kelas lamun menjadi pasir yaitu kelas lamun pada tahun 1998 seluas 82,8 ha mengalami perubahan menjadi pasir seluas 5,76 ha pada tahun 2018 .

6. Perubahan kelas lamun menjadi terumbu karang yaitu kelas lamun pada tahun 1998 seluas 82,8 ha mengalami perubahan menjadi terumbu karang seluas 0,21 ha pada tahun 2018.

Perubahan luas terumbu karang pada tahun 1998-2018 yang paling besar yaitu perubahan terumbu karang menjadi pasir seluas 9,13 ha atau sebesar 29,49\%, sedangkan perubahan paling kecil yaitu perubahan lamun menjadi terumbu karang seluas 0,21 ha atau sebesar $0,25 \%$. Pada kelas lainnya perubahan luasan paling besar yaitu perubahan lamun menjadi pasir seluas 5,76 ha atau sebesar $6,96 \%$, sedangkan perubahan paling kecil yaitu perubahan pasir menjadi lamun seluas 2,67 ha atau sebesar $17,35 \%$.

\subsection{Matriks Konfusi}

Berdasarkan data koordinat lapangan dapat dilakukan uji akurasi yang dikombinasikan dengan matriks konfusi.

Dari hasil klasifikasi citra dengan menggunakan klasifikasi unsupervised dan dengan menggunakan verifikasi data lapangan, maka didapatkan akurasi pada penelitian ini yaitu diperoleh presentasi 
producer accuracy (untuk mengetahui tingkat akurasi berdasarkan fakta yang diperoleh di lapangan) sebesar 95,23\% untuk kelas terumbu karang, pada kelas pasir sebesar $90 \%$, dan pada kelas lamun sebesar $80 \%$. Sedangkan nilai user's accuracy (untuk mengetahui ketelitian hasil klasifikasi terhadap seluruh obyek yang dapat diidentifikasi) sebesar 90,90\% untuk kelas terumbu karang, pada kelas pasir sebesar 100 $\%$, dan pada kelas lamun sebesar $80 \%$. Sedangkan untuk nilai overall accuracy sebesar 91,66\% dan nilai koefisien kappa sebesar 0,848. Hal ini menunjukkan bahwa hasil producer's accuracy, user's accuracy, dan overall accuracy sudah baik dan dapat diterima menurut Purwadhi (2001) karena lebih dari $70 \%$. Menurut Purwadhi (2001), bahwa nilai akurasi dari klasifikasi citra diharapkan lebih besar dari $70 \%$ sehingga dari nilai yang didapatkan tersebut dapat dijadikan pembuktian terhadap kesesuaian hasil klasifikasi citra dengan kondisi di lapangan. Pada hasil klasifikasi yang telah diuji akurasinya, didapatkan hasil luasan yang diinginkan. Klasifikasi yang didapatkan pada penelitian ini dibagi menjadi tiga kelas yaitu terumbu karang, pasir, dan lamun. Pembagian kelas-kelas tersebut mengacu pada data lapangan di lokasi penelitian. Luasan yang didapatkan berpengaruh terhadap uji akurasi yang didapatkan. Jika akurasi yang didapatkan buruk, mak hasil luasan dari klasifikasi citra juga akan ikut berubah.

\section{KESIMPULAN DAN SARAN}

\subsection{Kesimpulan}

Berdasarkan analisis yang dilakukan dalam penelitian ini, maka dapat ditarik kesimpulan sebagai berikut:

1. Dengan menggunakan teknologi penginderaan jauh memanfaatkan sinar radiasi elektromagnetik pada spektrum band biru dengan panjang gelombang $(0,452 \mu m-0,512 \mu m)$ dan band hijau dengan panjang gelombang $(0,533 \mu \mathrm{m}$ $0,590 \mu \mathrm{m}$ ) menggunakan algoritma
Lyzenga dapat menembus air sehingga dapat mendeteksi terumbu karang.

2. Dari hasil pengolahan citra landsat menggunakan algoritma lyzenga serta dilakukan uji akurasi menggunakan matriks konfusi dapat disimpulkan bahwa terjadi perubahan dan pengurangan luasan terumbu karang dari tahun 1998 - 2018. Kelas terumbu karang mengalami pengurangan luasan seluas 11,22 ha pada tahun 1998-2018.

3. Trend perubahan luasan pada kelas terumbu karang mengalami penurunan dari tahun ke tahun dan luasan cenderung berkurang, yaitu penurunan seluas 3,82 ha pada tahun 2008, 5,47 ha pada tahun 2015, dan 1,93 ha pada tahun 2018.

4. Berdasarkan hasil pengamatan di lapangan pengurangan luasan terumbu karang di Pulau Tegal disebabkan karena faktor alam dan faktor manusia. Kerusakan terumbu karang yang disebabkan faktor alam diantaranya suhu, ombak, dan arus. Sedangkan kerusakan terumbu karang yang disebabkan faktor manusia yaitu pengeboman, penambangan karang untuk bahan bangunan dan souvenir, kerusakan karang akibat jangkar kapal, kegiatan budidaya laut dan wisata.

5. Berdasarkan hasil klasifikasi citra dengan menggunakan klasifikasi unsupervised dan dengan menggunakan verifikasi data lapangan, maka didapatkan akurasi pada penelitian ini yaitu diperoleh presentasi producer accuracy sebesar 95,23\% untuk kelas terumbu karang, pada kelas pasir sebesar $90 \%$, dan pada kelas lamun sebesar $80 \%$. Sedangkan nilai user's accuracy sebesar 90,90\% untuk kelas terumbu karang, pada kelas pasir sebesar $100 \%$, dan pada kelas lamun sebesar $80 \%$. Sedangkan untuk nilai overall accuracy sebesar 91,66 \% dan nilai koefisien kappa sebesar 0,848 .

\subsection{Saran}

Hasil luasan dan uji akurasi dari metode klasifikasi Unsupervised dapat dikembangkan dengan membandingkan menggunakan metode yang lain seperti metode Brovey, Hue 
Saturation Intensity (HIS), dan algoritma Jupp.

\section{UCAPAN TERIMA KASIH}

Penulis mengucapkan terima kasih kepada Tuhan YME yang telah memberikan nikmat yang tak terhingga dalam menyelesaikan penelitian ini.

\section{DAFTAR PUSTAKA}

Hartoni, 2011, Kondisi Terumbu Karang di Perairan Pulau Tegal dan Sidodadi Kecamatan Padang Cermin Kabupaten Pesawaran Provinsi Lampung, Maspari Journal, vol 4, hal 46-57.

Jaelani, L. M., Limehuwey, R., Kurniadin, N., Pamungkas, A., Koenhardono, E. S., \& Sulisetyono, A, 2016, Estimation of Total Suspended Sediment and Chlorophyll-A Concentration from Landsat 8-Oli: The Effect of Atmospher and Retrieval Algorithm, IPTEK The Journal for Technology and Science, vol 5, hal 56-64.

Lillesand and Kiefer, 1979, Remote Sensing and Image Interpretation, Jurnal Kelautan, vol 3, hal 18-28.

Lyzenga, D. R., 1978, Passive Remote Sensing Techniques for Mapping Water Depth and Bottom Features,
International journal of remote sensing, vol.10, no.2, hal 71-82.

Lyzenga, D. R., 1981, Remote Sensing of Bottom Reflectance and Water Attenuation Parameters in Shallow Water Using Aircraft and Landsat Data, International Journal Remote Sensing, vol 10, no.2, hal 72-82.

Purwadhi, F. S. H., 2001, Interpretasi Citra Digital, Jurnal Ilmu dan Teknologi Kelautan Tropis, vol 10, hal 99-109.

Susilo, S. B., 1997, Penginderaan Jauh untuk Mangrove, Zaenudin, A.N., Pemetaan Terumbu Karang, Ghalia Indonesia, Bogor.

Siregar, V.P., 2010, Pemetaan Substrat Dasar Perairan Dangkal Karang Congkak dan Lebar Kepulauan Seribu Menggunakan Citra Satelit Quickbird, EJurnal Ilmu dan Teknologi Kelautan Tropis, vol 2, hal 19-30.

Suharsono, 1998, Conditions of Coral Reef Resources in Indonesia, Paper dalam Jurnal Pesisir dan Lautan, vol 10, no.2, hal 71-82.

Yusuf, M., 2013, Kondisi Terumbu Karang dan Potensi Ikan di Perairan Taman Nasional Karimunjawa, Kabupaten Jepara, Buletin Oseanografi Marina, vol 2, hal 54-60. 


\section{LAMPIRAN}

Tabel 1. Tabel matrix confusion kolom air Lyzenga tahun 2018 menggunakan verifikasi data lapangan

\begin{tabular}{|c|c|c|c|c|c|c|}
\hline Lapang & $\begin{array}{c}\text { Terumbu } \\
\text { Karang }\end{array}$ & Pasir & Lamun & Total & $\begin{array}{l}\text { Producer } \\
\text { Accuracy }\end{array}$ & $\begin{array}{c}\text { User } \\
\text { Accuracy }\end{array}$ \\
\hline $\begin{array}{c}\text { Terumbu } \\
\text { Karang }\end{array}$ & 20 & 1 & 1 & 22 & $95,23 \%$ & $90,90 \%$ \\
\hline Pasir & & 9 & & 9 & $90 \%$ & $100 \%$ \\
\hline Lamun & 1 & & 4 & 5 & $80 \%$ & $80 \%$ \\
\hline Total & 21 & 10 & 5 & 36 & & \\
\hline
\end{tabular}

Tabel 2. Perhitungan perbedaan luasan kelas tahun $1998-2018$

\begin{tabular}{|c|c|c|c|c|c|c|c|}
\hline \multicolumn{2}{|c|}{ Tahun 1998} & \multicolumn{6}{|c|}{ Perubahan tahun 2018} \\
\hline \multirow{2}{*}{$\begin{array}{l}\text { Nama } \\
\text { Kelas }\end{array}$} & \multirow{2}{*}{$\begin{array}{l}\text { Luas } \\
\text { (ha) }\end{array}$} & \multicolumn{2}{|c|}{$\begin{array}{l}\text { Terumbu } \\
\text { Karang }\end{array}$} & \multicolumn{2}{|c|}{ Pasir } & \multicolumn{2}{|c|}{ Lamun } \\
\hline & & $\begin{array}{l}\text { Luas } \\
\text { (ha) }\end{array}$ & $\%$ & $\begin{array}{l}\text { Luas } \\
\text { (ha) }\end{array}$ & $\%$ & $\begin{array}{l}\text { Luas } \\
\text { (ha) }\end{array}$ & $\%$ \\
\hline $\begin{array}{c}\text { Terumbu } \\
\text { Karang }\end{array}$ & 30,96 & 17,45 & 56,36 & 9,13 & 29,49 & 4,38 & 14,15 \\
\hline Pasir & 15,39 & 2,08 & 13,52 & 9,53 & 61,92 & 2,67 & 17,35 \\
\hline Lamun & 82,8 & 0,21 & 0,25 & 5,76 & 6,96 & 78,11 & 94,34 \\
\hline Total & 129,15 & 19,74 & 15,28 & 24,42 & 18,91 & 85,16 & 65,94 \\
\hline
\end{tabular}




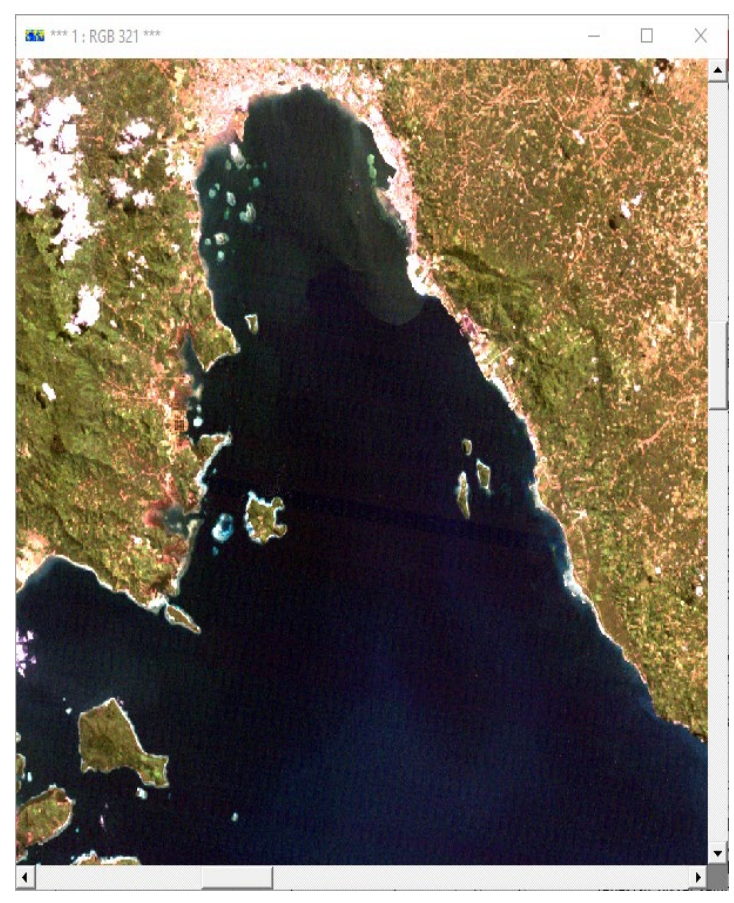

Gambar 1. Hasil Penajaman Citra Landsat

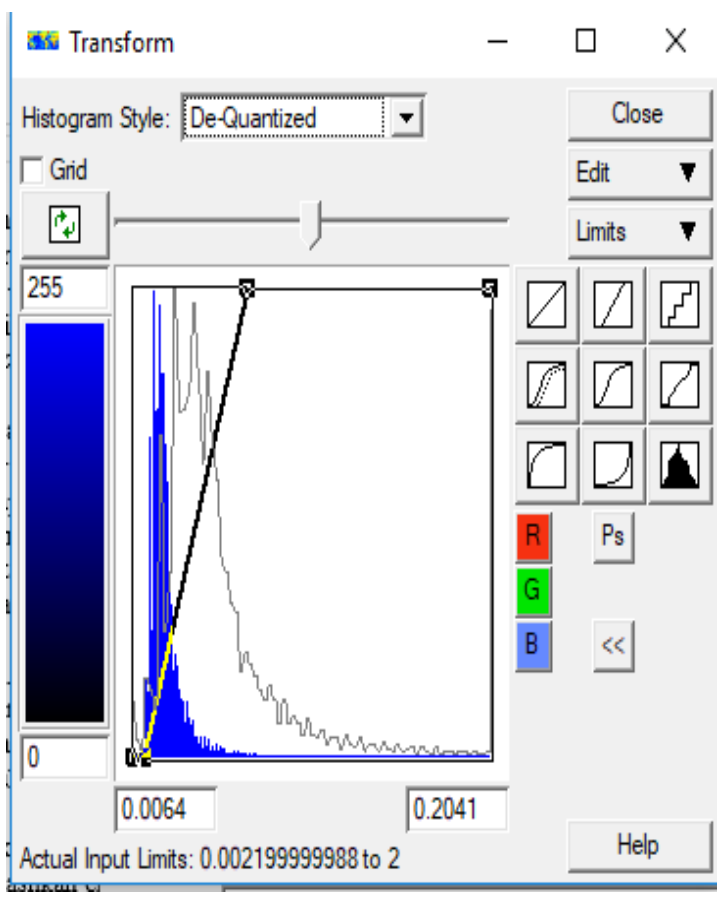

Gambar 2. Histogram Penajaman Citra

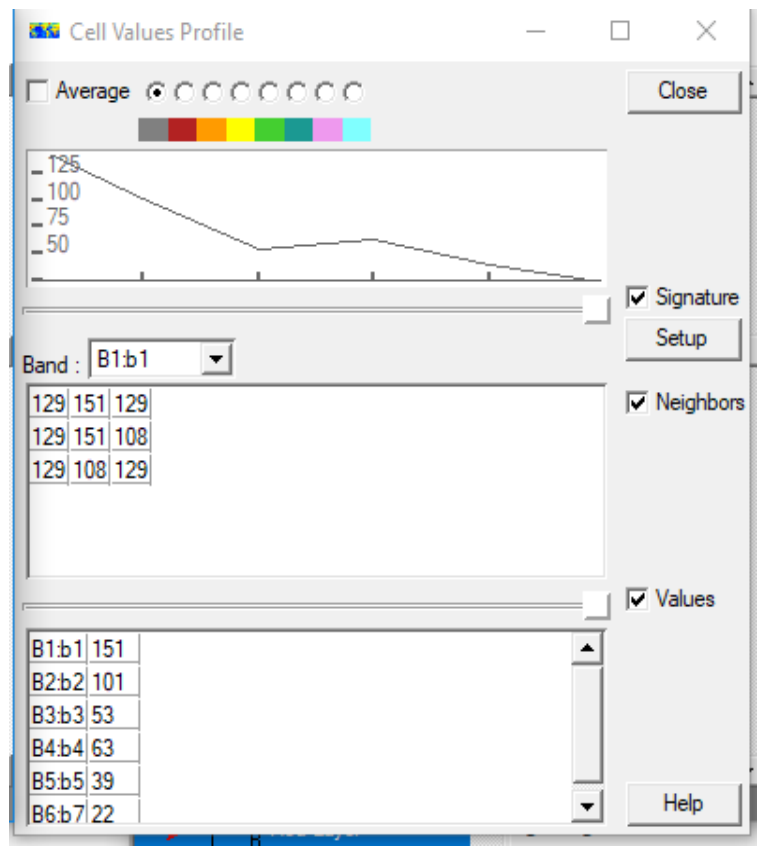

(a)

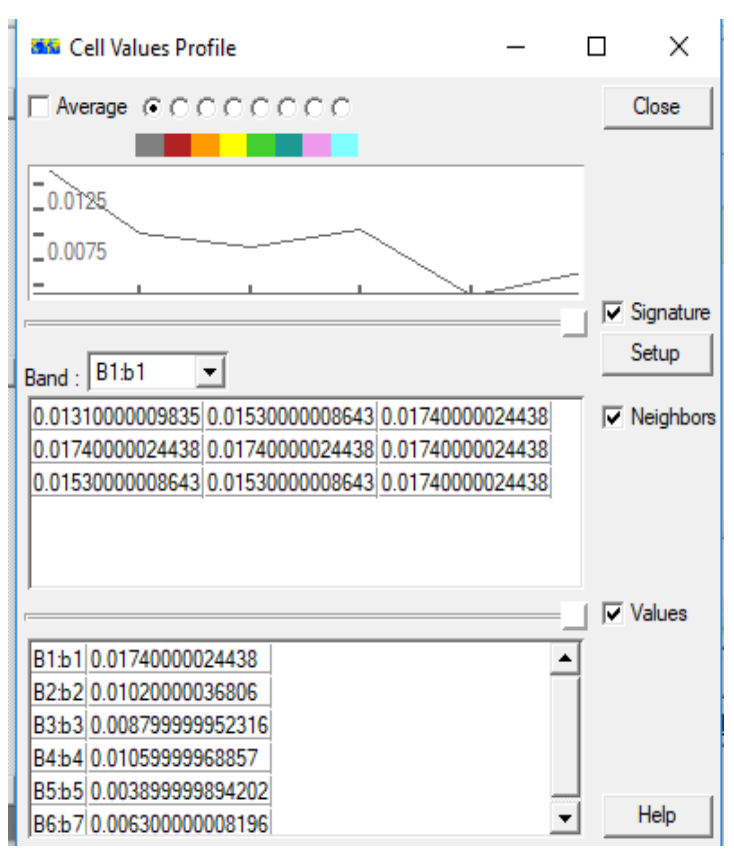

(b)

Gambar 3. Sebelum (a) dan sesudah (b) koreksi atmosfer citra 


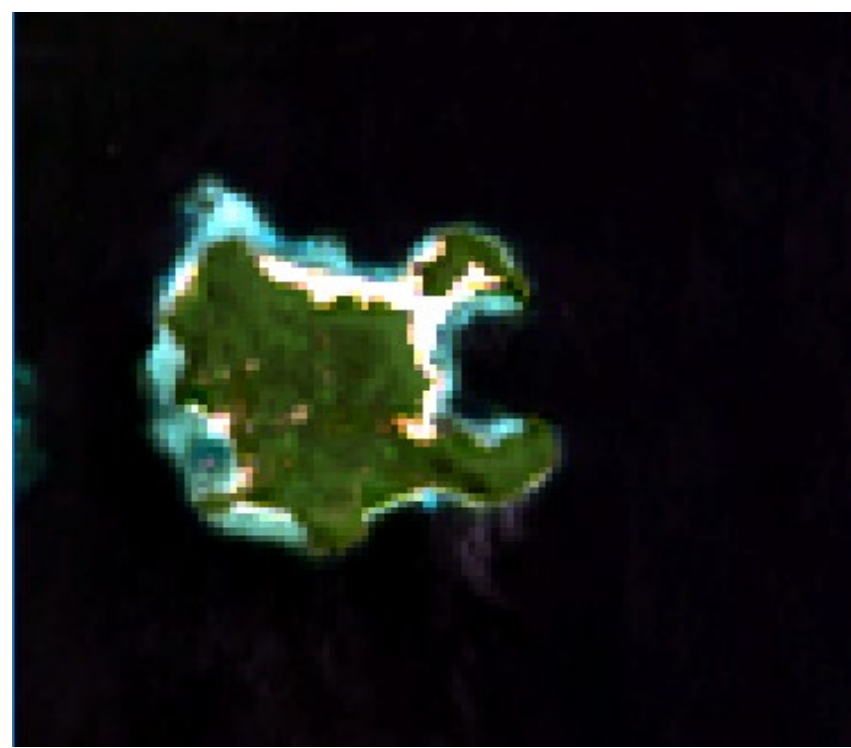

Gambar 4. Pulau Tegal (Citra Landsat Resolusi Spasial 30 meter)

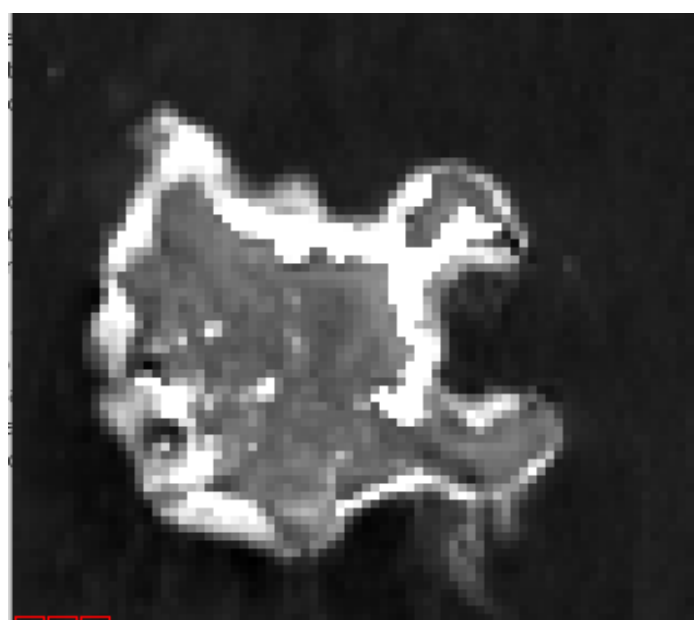

Gambar 5. Mask band 4 dan band 3

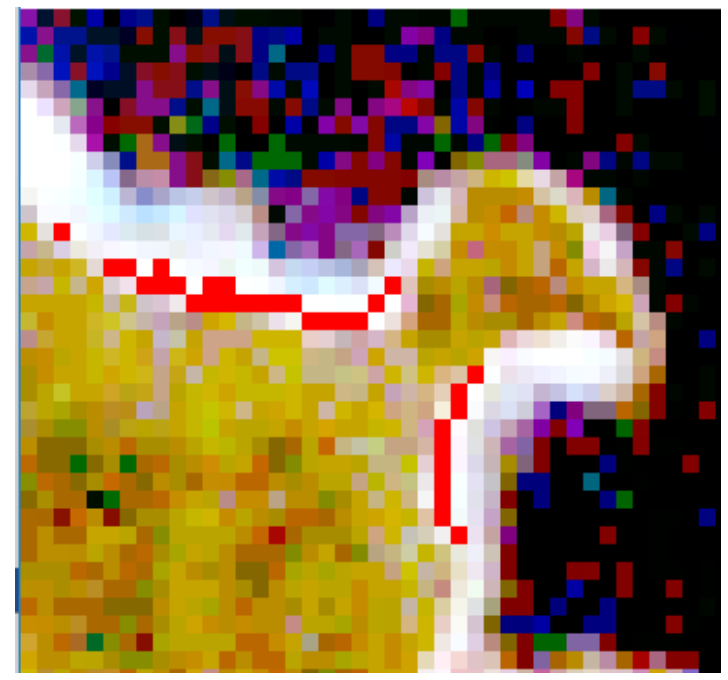

Gambar 6. Data ROI menandai wilayah pasir 


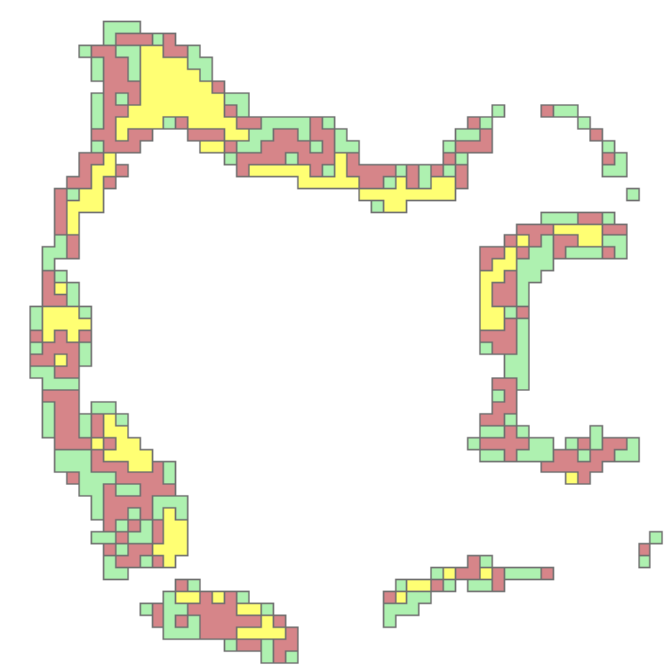

Gambar 7. Hasil klasifikasi

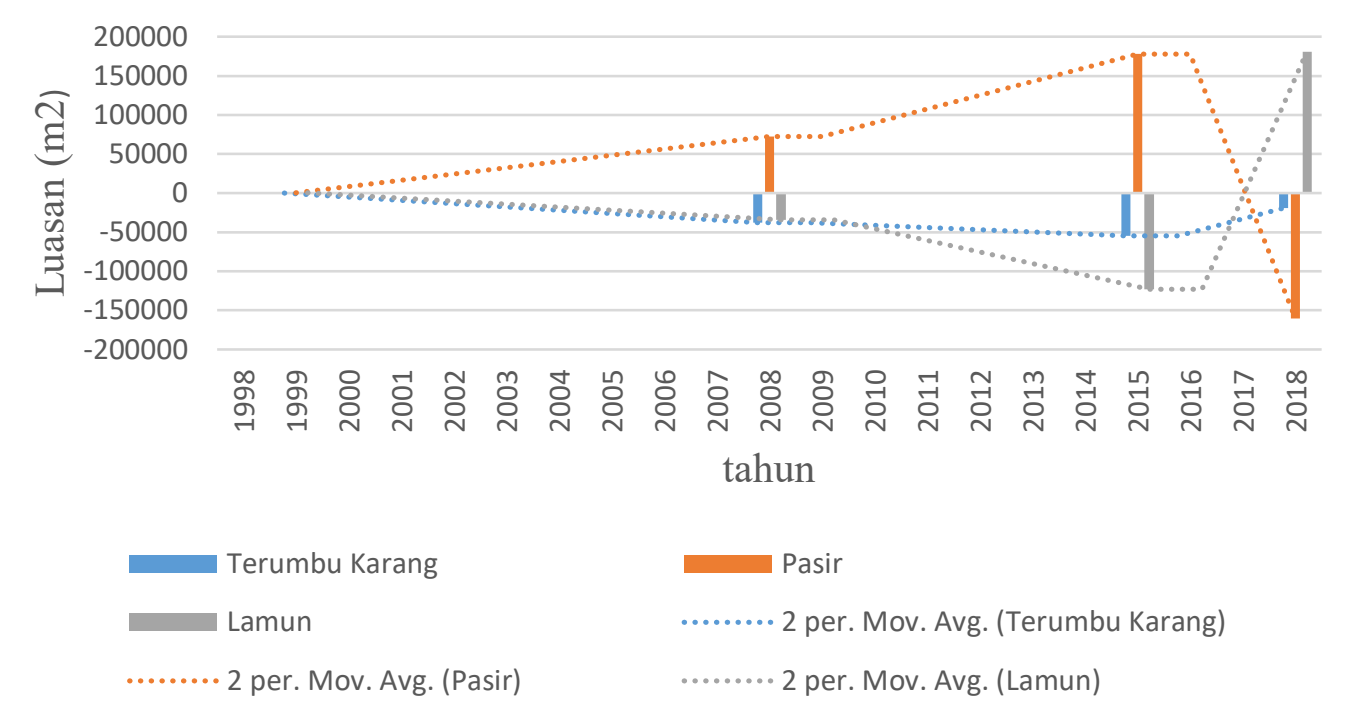

Gambar 8. Grafik trend perubahan luasan kelas tahun 1998-2018 